\title{
Pierre Gringore, Les entrées royales à Paris de Marie d'Angleterre (1514) et Claude de France (1517)
}

\section{Michele Mastroianni}

\section{(2) OpenEdition}

1 Journals

\section{Edizione digitale}

URL: http://journals.openedition.org/studifrancesi/27352

DOI: 10.4000/studifrancesi.27352

ISSN: 2421-5856

\section{Editore}

Rosenberg \& Sellier

\section{Edizione cartacea}

Data di pubblicazione: 31 décembre 2006

Paginazione: 587

ISSN: 0039-2944

\section{Notizia bibliografica digitale}

Michele Mastroianni, «Pierre Gringore, Les entrées royales à Paris de Marie d'Angleterre (1514) et Claude de France (1517) », Studi Francesi [Online], 150 (L | III) | 2006, online dal 30 novembre 2015, consultato il 08 novembre 2020. URL : http://journals.openedition.org/studifrancesi/27352 ; DOI : https://doi.org/ 10.4000/studifrancesi.27352

\section{Questo documento è stato generato automaticamente il 8 novembre 2020}

\section{(c) (1)}

Studi Francesi è distribuita con Licenza Creative Commons Attribuzione - Non commerciale - Non opere derivate 4.0 Internazionale. 


\title{
Pierre Gringore, Les entrées royales à Paris de Marie d'Angleterre (1514) et Claude de France (1517)
}

\author{
Michele Mastroianni
}

\section{NOTIZIA}

PIERRE GRINGORE, Les entrées royales à Paris de Marie d'Angleterre (1514) et Claude de France (1517), édition par Cynthia J. BRown, Genève, Droz («Textes Littéraires Français», 577), 2005, pp. 360 .

1 C. J. Brown che aveva già pubblicato, in un primo volume delle opere complete di Pierre Gringore, le Euvres polémiques (Genève, Droz, 2003: cfr. questi «Studi», 142, 2004, p. 167), prosegue l'impresa con un secondo volume, contenente l'edizione dell'Entrée de Marie d'Angleterre à Paris (la prima edizione moderna, del 1934, ad opera di Ch. R. Baskervill è oggi introvabile) e dell'Entrée de Claude de France à Paris (per la prima volta edita). Entrambi i testi sono minuziosamente annotati. Come le CEuvres polémiques del precedente volume, le Entrées sono opere politiche, e non soltanto celebrative e descrittive, nel senso che non solo sono manifesti della regalità, ma sottintendono una promozione del proprio mestiere e degli interessi corporativi di un autore che era il responsabile della produzione dei misteres commissionati dalla città di Parigi e, nello stesso tempo, l'organizzatore ufficiale dei cosiddetti théâtres d'entrée. È il sottile gioco e complesso intreccio di interrelazioni fra le varie forme di propaganda e committenza ad essere messo in luce nella ricca e documentatissima introduzione, che allarga i suoi interessi a una serie di altre pièces, anonime o non di Gringore, concernenti entrées e couronnements reali, nella fattispecie i rendiconti delle Entrées à Paris di Anna di Bretagna (del 1492 e del 1504), i resoconti anonimi dell'entrée di Maria d'Inghilterra e alcune versioni anonime dell'entrée di Claudia di Francia. Tutti questi testi sono editi sulla base di un esemplare riscontro dei testimoni esistenti e, come già il volume precedente, offrono materiale e strumenti utili per lo storico della lingua, oltre a un 
accurato studio linguistico. Essendo, inoltre, prodotti concepiti come manoscritti preziosamente miniati, in un momento in cui l'opera celebrativa e di propaganda passava dal codice al libro a stampa (secondo un itinerario pubblicistico seguito dallo stesso Gringore), queste Entrées offrono adito a riflessioni sulla funzione 'politica' del manoscritto e del testo stampato. 